\title{
Estimating the rate and determinants of exclusive breastfeeding practices among rural mothers in Southern Ghana
}

\author{
Alfred Kwesi Manyeh ${ }^{1,2,3^{*}} \mathbb{D}$, Alberta Amu ${ }^{1,4}$, David Etsey Akpakli, ${ }^{1,4}$, John E. Williams ${ }^{1,4}$ and Margaret Gyapong ${ }^{3}$
}

\begin{abstract}
Background: The health benefits of exclusive breastfeeding practices in both the short and long term accrue to breastfed infants, mothers, families and the society at large. Despite the evidence of these benefits and adoption of various World Health Organization (WHO) strategies on promotion of exclusive breastfeeding by Ghana, the increase in the rate of exclusive breastfeeding has been very slow in the country. This study aimed to estimate the rate and investigate socio-economic and demographic determinants of 6 months exclusive breastfeeding in two rural districts in Southern Ghana.
\end{abstract}

Methods: Pregnancy, childbirth, breastfeeding, demographic and socioeconomic information of 1870 women who were prospectively registered by the Dodowa Health and Demographic Surveillance System and gave birth between 1 January 2011 and 31 December 2013 was extracted. The proportion of 6 months exclusive breastfeeding among the study participants was estimated and the relationship between the dependent and the independent variables were explored using logistics regression model at 95\% confidence level.

Results: The proportion of mothers who exclusive breastfed for 6 months in the study was $71.0 \%$. Mothers aged 25-29 and 30 + years are 93 and 91\% respectively more likely to practice 6 months exclusive breastfeeding compared to those aged < 20 years (OR 1.93, $95 \% \mathrm{Cl} 1.25,2.99$, OR 1.91, $95 \% \mathrm{Cl} 1.91,3.08)$. The odds of artisan mothers practicing 6 months exclusive breastfeeding is 36\% less likely compared to those unemployed (OR 0.64, $95 \% \mathrm{Cl} 0.43,0.96)$. There is a higher chance that $45 \%$ of mothers with a household size of more than five members to practice exclusive breastfeeding compared to those with household size of less than six $(\mathrm{OR} 1.45,95 \% \mathrm{Cl} 1.16$, 1.81). Women in the fishing district were $85 \%$ less likely to practice 6 months exclusive breastfeeding compared to those in farming district (OR $0.15,95 \% \mathrm{Cl} 0.12,0.20)$.

Conclusion: There is high rate of exclusive breastfeeding in the study area. Maternal age, type of occupation, household size and district of residence are determinants of 6 months exclusive breastfeeding among the study participants.

Keywords: Exclusive breastfeeding, Child health, Demographic surveillance, Dodowa, Ghana

\footnotetext{
* Correspondence: alfredmanyeh4u@gmail.com

'Dodowa Health Research Centre, Dodowa, Ghana

${ }^{2}$ Division of Epidemiology and Biostatistics, School of Public Health,

University of the Witwatersrand, Johannesburg, Parktown, South Africa

Full list of author information is available at the end of the article
}

(c) The Author(s). 2020 Open Access This article is distributed under the terms of the Creative Commons Attribution 4.0 International License (http://creativecommons.org/licenses/by/4.0/), which permits unrestricted use, distribution, and reproduction in any medium, provided you give appropriate credit to the original author(s) and the source, provide a link to the Creative Commons license, and indicate if changes were made. The Creative Commons Public Domain Dedication waiver (http://creativecommons.org/publicdomain/zero/1.0/) applies to the data made available in this article, unless otherwise stated. 


\section{Background}

The association between child health and development outcomes with appropriate breastfeeding practices such as early initiation at birth, exclusive breastfeeding during the first 6 months of life, and breastfeeding for at least 2 years has been established [1,2]. A baby's diet during the first few months of life has a significant role on the composition and stability of the gut microbiome that can only be acquired after birth [3]. These bacteria make digestion of solids easier, thus, preventing gut problems and illnesses at later stage of life [3]. The World Health Organization (WHO) endorsed exclusive breastfeeding as an optimal way to feed infants [4]. Exclusive breastfeeding is defined by WHO as feeding an infant exclusively with breast milk for the first 6 months of life. During this period, the infant may be given drops of vitamins, minerals and Oral Rehydration Solution, if prescribed [4]. The WHO and UNICEF recommendations on breastfeeding includes: commencement of breastfeeding within the first hour after childbirth; exclusive breastfeeding for the first 6 months after birth; and sustained breastfeeding for 2 years or more, coupled with safe, nutritionally suitable, age appropriate, responsive complementary feeding starting in the 6 month [5].

An enhanced breastfeeding practice is known to have reduced child morbidity and mortality, improved quality of life, and enriched human capital [1, 2]. Breastfeeding is also associated with positive maternal outcomes such as reduced likelihood of breast and ovarian cancer, diabetes, and increased birth spacing [6]. In countries where child survival and growth are often endangered by infectious diseases and malnutrition, the benefits of enhanced breastfeeding practices cannot be over emphasized [7-10].

Exclusive breastfeeding practices are influenced by multiple factors. These include health, psychosocial, cultural, social, and economic factors $[11,12]$. Studies have shown that the decisions regarding exclusive breastfeeding in low-income countries are influenced by education, employment, place of delivery, family pressure, and cultural values [13-15].

Other studies have shown that mixed feeding is associated with increased diarrhea and pneumonia/respiratory diseases in children [16-20]. Infants who were not exclusively breastfed have a $165 \%$ higher likelihood of suffering from diarrhea and 107\% higher likelihood of pneumonia than children who were exclusively breastfed $[17,20]$.

Despite the evidence on benefits of exclusive breastfeeding, in 2016 only $43 \%$ of infants were exclusively breastfed globally [21]. The rate is lower (37\%) in low and middle income countries [2]. Despite high child mortality and malnutrition in Sub Saharan Africa (SSA), only $36 \%$ of the infants were exclusively breastfed in $2016[8,21,22]$.
In 2017, infant and under-5 mortality rates for Ghana were 37 and 52 deaths per 1000 live births, respectively. The neonatal mortality rate for the same period was 25 deaths per 1000 live births. At these mortality levels, one out of 19 Ghanaian children does not survive to their fifth birthday [23].

Although Ghana adopted various WHO strategies to promote exclusive breastfeeding, there has been a slow increase in the rates of exclusive breastfeeding in the country. The 2011 Ghana Multiple Indicator Cluster Survey (MICS) in 2011 reported that less than half (46\%) of all infants aged 0-6 months in Ghana were exclusively breastfed [24]. This level is lower than that recommended by WHO/UNICEF.

In Ghana, $52 \%$ of children younger than 6 months were exclusively breastfed in 2014 [25]. According to the 2014 Ghana Demographic and Health Survey (GDHS) the percentage of children aged 0-5 months who were exclusively breastfed has decreased by $17 \%$ between 2008 and 2014 [25]. The percentage of children who were bottle fed appears to have increased over the past decade. In 2003 and 2014, 11 and 16\% of children under 6 months, respectively, were bottled fed [25]. The 2014 GDHS shows that the country still faces the challenges of high infant mortality of 41 deaths per 1000 live births and 19\% of children were stunted ascribable to malnutrition and infections [25].

Using data from an open cohort longitudinal population, we estimated the rate of exclusive breastfeeding, examined socio-economic and demographic factors influencing exclusive breastfeeding practices in two rural districts in Southern Ghana.

\section{Methods}

\section{Study area and data source}

This study was conducted in the Shai-Osudoku and Ningo-Prampram districts of the Greater Accra Region of Ghana. The two districts cover a total population of 115,754 individuals living in 380 communities in 23,647 households [26]. A comprehensive description of the study districts and the operations of Dodowa Health and Demographic Surveillance System (DHDSS) can be found elsewhere [27-29]. Health service delivery in the study districts is provided by government hospitals, health centres, clinics, Community-based Health and Planning Services (CHPS) compounds/zones, missions and non-governmental health facilities $[26,27]$. The secondary data was extracted from the longitudinal population-based database of the DHDSS. The extracted data was exported to STATA version 14.2 for cleaning, coding and analysis.

\section{Study population}

All women resident in the two study districts who were registered in the DHDSS and gave birth between January 
1, 2011 and December 31, 2013 were included in the study. The index baby must at least be 6 months old at the time of interview to qualify the mother to participate in the study. Women who were not registered in the DHDSS, those who delivered before 1 January 2011 or after 31 December 2013 and those whose babies were less than 6 months at the time of the interview were excluded from the study. A total of 1870 mothers were included in the study.

\section{Variables}

\section{Dependent variable}

The dependent variable is breastfeeding and it was coded as 1 for 6 months exclusive breastfeeding and 0 if otherwise. Six months exclusive breastfeeding in this study is defined as feeding infants with only breast milk, without supplemental liquids or solids except for liquid medicine and vitamin or mineral supplements for the first 6 months of life [25]. This is based on UNICEF and WHO recommendation [30]. Questions on exclusive breastfeeding was administered to all women who gave birth between January 1, 2011 and December 31, 2013. The question was asked retrospectively from the time of birth to the first 6 months of life of the index child.

\section{Independent variables}

From the available DHDSS data, we extracted nine independent variables which includes; maternal age, educational level, marital status, parity, timing of antenatal clinic initiation, place of delivery, educational level of household head, district of residence and socioeconomic status. Being "married" in this study refers to performance of a legal marriage ceremony including payment of bride price; "cohabitation" is when a man and a woman live together for the purpose of marriage without a legal marriage ceremony and without payment of bride price.

"Timing of antenatal clinic initiation" is the period during pregnancy when the expectant mother started accessing antenatal care (ANC) services. The "timing of antenatal clinic initiation" in this is grouped into three categories (first, second and third trimesters).

The socio-economic status is estimated using weights derived from principal component analysis (PCA) through household social status, ownership of assets, availability of utilities among others [26, 27]. Household socioeconomic status is a proxy measure of a household's long term standard of living [27]. The proxies from the PCA were divided into five quintiles; poorest, poorer, middle, richer and richest $[26,27]$. Selection of these variables was also based on literature and the likelihood to influence the outcome of interest.

\section{Statistical analysis}

A descriptive analysis of sociodemographic characteristics of the participants was carried out. The proportion of exclusive breastfeeding among the study participants was estimated as: (Number of infants born between 1 January 2011 and 31 December 2013 who were exclusively breastfed / Total number of infants born between 1 January 2011 and 31 December 2013) $\times 100$. The association between the dependent and the independent variables was explored using logistic regression model. The independent variables that were significant at $p<0.05$ in the crude logistic regression model were entered together into an adjusted model. Data analysis was done using Stata version 14.2 and the results was presented in tables with summary statistics at 95\% confidence intervals $(\mathrm{CI})$.

\section{Results}

\section{Sociodemographic information}

Table 1 presents the sociodemographic information of study participants. The mean age was 27.9 years $(\mathrm{SD}=$ 7.2). The majority of the study participants $(72.78 \%)$ were of the Ga-Dangme ethnic group and a large proportion (91.2\%) were of the Christian faith. More than half $(61.0 \%)$ of the participants' households were headed by males with an average household size was 6.5. A large percentage $(71.2 \%)$ of study participants delivered in a health facility. More than half $(64.0 \%)$ of the study participants initiated antenatal clinic visits in the second trimester of their last pregnancy. The proportion of mothers who exclusively breastfed for 6 months was $71.0 \%$.

\section{Unadjusted and adjusted odds ratio of determinants of exclusive breastfeeding}

Table 2 presents the unadjusted and adjusted Odds Ratio (OR) at $95 \%$ CI of socioeconomic and demographic determinants of 6 months exclusive breastfeeding in the Dodowa Health and Demographic Surveillance site. In the unadjusted model, maternal age, occupation, place of delivery, parity, household size and sex of household head had statistically significant associations with 6 months exclusive breastfeeding.

Women aged 25-29 and 30 + years were 53 and 75\% more likely to practice exclusive breastfeeding respectively compared to those aged $<20$ years (COR $1.53,95 \%$ CI 1.10, 2.13, COR 1.75, 95\% CI 1.28, 2.40). This was statistically significant.

A similar pattern was observed in the adjusted model such that in the presence of other explanatory variables, the odds of mothers practicing 6 months exclusive breastfeeding increased with increasing maternal age. The odds of mothers aged 25-29 and $30+$ years were 93 and $91 \%$ respectively more likely to practice 6 months 
Table 1 Sociodemographic characteristics of the study participants

\begin{tabular}{lll}
\hline Characteristics & Frequency $^{\text {a }}$ & Proportion (\%) \\
\hline Age group (in years) & & \\
$<20$ & 231 & 12.4 \\
$20-24$ & 424 & 22.7 \\
$25-29$ & 483 & 25.8 \\
$30+$ & 732 & 39.1
\end{tabular}

Mean $=27.89(\mathrm{sd}=7.15)$

Ethnicity

$$
\text { Ga-Dangme }
$$

Akan

Ewe

Mole- Dagbani

Other tribes

Religion

Christianity
Islam
Traditional
Other religion

Occupation

Unemployed

Farmer

Artisan

Trader

Civil servant

Student

Others

Level of education

No education

Primary

Junior high school level

Senior high school level and above

Marital status

Single
Married
Separated/divorced
Cohabiting
Sex of household head

Female

Male

Household size

Less than six

More than five

Mean $=6.45(S D=4.33)$

District of residence
Table 1 Sociodemographic characteristics of the study participants (Continued)

\begin{tabular}{lll}
\hline Characteristics $^{\prime}$ & Frequency $^{\text {a }}$ & Proportion (\%) \\
\hline Shai-Osudoku & 836 & 44.7 \\
$\quad$ Ningo-Prampram & 1034 & 55.3 \\
Parity & & \\
Parity 1 & 520 & 27.8 \\
Parity 2 & 429 & 22.9 \\
Parity 3 & 374 & 20.0 \\
Parity3+ & 547 & 29. \\
Delivery place & & \\
Health facility & 1332 & 71.23 \\
Outside health facility & 538 & 28.8 \\
Timing of ANC initiation & & \\
First trimester & 525 & 28.1 \\
Second trimester & 1196 & 64.0 \\
Third trimester & 147 & 7.9 \\
Babies age at time of interview & $0.5-1.6$ years & \\
Breastfeeding type & & \\
Not exclusive & 543 & 29.0 \\
Exclusive & 1327 & 71.0 \\
Exclusive breastfeeding rate & $\mathbf{7 1 . 0 \%}$ & \\
\hline
\end{tabular}

$n=1870 ; S D$ standard deviation ${ }^{a}$ number of respondents across some categories may not add up to 1870 due to missing data

exclusive breastfeeding compared to those aged $<20$ years (AOR 1.93, 95\% CI 1.25, 2.99, AOR 1.91, 95\% CI $1.91,3.08)$. This was statistically significant.

There was a statistically significant association between occupation and women practicing 6 months exclusive breastfeeding. The odds of a farmer practicing exclusive breastfeeding was $77 \%$ more likely compared to those unemployed (COR 1.77, 95\% CI 1.23, 2.55).

In the adjusted model, the odds of female artisans to practice 6 months exclusive breastfeeding was 36\% less likely compared to those unemployed (AOR 0.64, 95\% CI 0.43, 0.96).

In the unadjusted model, the odds of women who delivered outside health facility to practice 6 months exclusive breastfeeding was $51 \%$ more likely compared to those who delivered in a health facility (COR 1.51, 95\% CI 1.20, 190). This association was not statistically significant (AOR 1.13, 95\% CI 0.87, 1.46) in the adjusted model.

In the crude model, the odds of women with parities two to practice 6 months exclusive breastfeeding compared to those with parity one was $91 \%$ (COR 0.91, 95\% CI $0.79,1.36)$. There was an increased odd of 17 and $56 \%$ of mothers with parities three and more (OR 1.17, $95 \%$ CI $0.88,1.56$, OR 1.56, 95\% CI 1.19, 2.04). In the presence of other variables (age, occupation, place of 
Table 2 Unadjusted and adjusted odds ratios of factors associated with 6 months exclusive breastfeeding

\begin{tabular}{|c|c|c|c|c|}
\hline \multirow{2}{*}{$\begin{array}{l}\text { Characteristics } \\
\text { Age group (in years) }\end{array}$} & \multicolumn{2}{|l|}{ Crude } & \multicolumn{2}{|l|}{ Adjusted $^{b}$} \\
\hline & COR $(95 \% \mathrm{Cl})$ & $P$ - values & AOR $(95 \% \mathrm{Cl})$ & $P$ - values \\
\hline$<20$ & 1.00 & & 1.00 & \\
\hline $20-24$ & $1.24(0.89,1.74)$ & 0.205 & $1.46(0.98,2.15)$ & 0.060 \\
\hline $25-29$ & $1.53(1.10,2.13)^{\mathrm{a}}$ & 0.012 & $1.93(1.25,2.99)^{\mathrm{a}}$ & 0.003 \\
\hline $30+$ & $1.75(1.28,2.40)^{\mathrm{a}}$ & $<0.001$ & $1.91(1.91,3.08)^{\mathrm{a}}$ & 0.007 \\
\hline \multicolumn{5}{|l|}{ Marital status } \\
\hline Single & 1.00 & & & \\
\hline Married & $1.22(0.91,1.63)$ & 0.193 & & \\
\hline Separated/divorced & $0.83(0.40,1.70)$ & 0.606 & & \\
\hline Cohabiting & $0.94(0.74,1.19)$ & 0.595 & & \\
\hline \multicolumn{5}{|l|}{ Education } \\
\hline No education & 1.00 & & & \\
\hline Primary & $0.81(0.62,1.05)$ & 0.110 & & \\
\hline Junior school level & $1.03(0.79,1.34)$ & 0.844 & & \\
\hline SHS and above & $1.08(0.73,1.61)$ & 0.694 & & \\
\hline \multicolumn{5}{|l|}{ Occupation } \\
\hline Unemployed & 1.00 & & 1.00 & \\
\hline Farmer & $1.77(1.23,2.55)^{\mathrm{a}}$ & 0.002 & $1.24(0.82,1.87)$ & 0.296 \\
\hline Artisan & $0.70(0.49,1.00)^{\mathrm{a}}$ & 0.049 & $0.64(0.43,0.96)^{a}$ & 0.032 \\
\hline Trader & $0.91(0.69,1.21)$ & 0.512 & $1.04(0.76,1.43)$ & 0.805 \\
\hline Civil servant & $0.91(0.42,1.97)$ & 0.812 & $0.66(0.28,1.58)$ & 0.350 \\
\hline Student & $0.82(0.59,1.14)$ & 0.242 & $1.04(0.71,1.53)$ & 0.838 \\
\hline Others & $0.73(0.37,1.46)$ & 0.379 & $0.89(0.42,1.85)$ & 0.750 \\
\hline \multicolumn{5}{|l|}{ Delivery place } \\
\hline Health facility & 1.00 & & 1.00 & \\
\hline Outside health facility & $1.51(1.20,1.90)^{\mathrm{a}}$ & $<0.001$ & $1.13(0.87,1.46)$ & 0.367 \\
\hline \multicolumn{5}{|l|}{ Parity } \\
\hline Parity 1 & 1.00 & & 1.00 & \\
\hline Parity 2 & $0.91(0.79,1.36)$ & 0.793 & $0.91(0.66,1.26)$ & 0.593 \\
\hline Parity 3 & $1.17(0.88,1.56)$ & 0.285 & $0.95(0.66,1.38)$ & 0.802 \\
\hline Parity 3+ & $1.56(1.19,2.04)^{\mathrm{a}}$ & 0.001 & $1.12(0.75,1.66)$ & 0.585 \\
\hline \multicolumn{5}{|l|}{ Household size } \\
\hline Less than six & 1.00 & & 1.00 & \\
\hline More than five & $1.33(1.09,1.63)^{\mathrm{a}}$ & 0.005 & $1.45(1.16,1.81)^{\mathrm{a}}$ & 0.001 \\
\hline \multicolumn{5}{|l|}{ Socio-economic status } \\
\hline Poorest & 1.00 & & & \\
\hline Poorer & $1.04(0.76,1.43)$ & 0.809 & & \\
\hline Poor & $1.09(0.79,1.49)$ & 0.611 & & \\
\hline Less poor & $1.02(0.75,1.40)$ & 0.891 & & \\
\hline Least poor & $0.95(0.69,1.30)$ & 0.749 & & \\
\hline \multicolumn{5}{|l|}{ Timing of ANC } \\
\hline First trimester & 1.00 & & & \\
\hline Second trimester & $1.16(0.93,1.45)$ & 0.184 & & \\
\hline Third trimester & $1.27(0.84,1.91)$ & 0.254 & & \\
\hline
\end{tabular}


Table 2 Unadjusted and adjusted odds ratios of factors associated with 6 months exclusive breastfeeding (Continued)

\begin{tabular}{|c|c|c|c|c|}
\hline \multirow{2}{*}{$\begin{array}{l}\text { Characteristics } \\
\text { Age group (in years) }\end{array}$} & \multicolumn{2}{|l|}{ Crude } & \multicolumn{2}{|l|}{ Adjusted $^{\mathrm{b}}$} \\
\hline & COR $(95 \% \mathrm{Cl})$ & $P$ - values & AOR $(95 \% \mathrm{Cl})$ & $P$ - values \\
\hline \multicolumn{5}{|c|}{ Sex of household head } \\
\hline Female & 1.00 & & 1.00 & \\
\hline Male & $1.44(1.18,1.77)^{\mathrm{a}}$ & $<0.001$ & $1.19(0.95,1.49)$ & 0.124 \\
\hline \multicolumn{5}{|l|}{ District of residence } \\
\hline Shai-Osudoku & 1.00 & & 1.00 & \\
\hline Ningo-Prampram & $1.16(0.12,0.21)^{a}$ & $<0.001$ & $0.15(0.1,0.20)^{a}$ & $<0.001$ \\
\hline
\end{tabular}

$\mathrm{Cl}$ confidence interval, COR crude odd ratio, AOR adjusted odd ratio, ${ }^{a}$ statistically significant. ${ }^{\mathrm{b}}$ Correct classification rate of the model $=72.8 \%$

delivery, household size, sex of household head and district of residence), while there was reduced odds of 91 and $95 \%$ of women with parities two and three respectively to practice exclusive breastfeeding (AOR 0.91, 95\% CI $0.66,1.26$, AOR $0.95,95 \%$ CI $0.66,1.38$ ), there was increased odds of $12 \%$ for mothers with parity more than three (AOR 1.12, 95\% CI 0.75, 1.66) in the adjusted model.

There is an increased odds of 33 and $45 \%$ in the crude and adjusted model respective of mothers with household size more than five members to practice 6 months exclusive breastfeeding compared to those with household size of less than six (COR 1.33, 95\% CI 1.09, 1.63, AOR $1.45,95 \%$ CI 1.16, 1.81). This was also statistically significant.

In the crude analysis, participants who belong to poorer, poor and less poor socio-economic categories were 4,9 and $2 \%$ respectively more likely to practice 6 months exclusive breastfeeding compared to those in poorest category.

There was increased odds of 16 and $27 \%$ for participants who initiated antenatal visit in the second and third trimesters respectively to practice 6 months exclusive breastfeeding compared to those who initiated theirs in the first trimester (COR 1.16, 95\% CI 0.93, 1.45, COR 1.27, 95\% CI $0.84,1.91)$. The crude analysis showed a significant association of women whose households were headed by males being 44\% more likely to practice 6 months exclusive breastfeeding compared to those in female headed households (COR 1.44, 95\% CI 1.18, 1.77).

The district of residence of participant was statistically significantly associated with practicing 6 months exclusive breastfeeding; there was an increased odds of $16 \%$ for women from Ningo-Prampram district compared to those from Shai-Osudoku district in the unadjusted analysis (COR 1.16, 95\% CI 0.12, 0.21). The odds ratio was reduced in the adjusted model to 0.15 (AOR 0.15, 95\% CI $0.12,0.20$ ). This was statistically significant.

\section{Discussion}

The aim of this study was to estimate the rate and examine socio-economic and demographic determinants of exclusive breastfeeding in two rural districts (NingoPrampram and Shai-Osudoku Districts) of Southern Ghana.

The exclusive breastfeeding rate among the study participants in this study was $71.0 \%$. This rate was higher than 52\% (24-h period exclusive breastfeeding) reported by 2014 GDHS [25] but lower than $84.3 \%$ (6 months exclusive breastfeeding) report by another Ghanaian study [31].

Maternal age, type of occupation, household size and district of residence appear to be strong determinants of exclusive breastfeeding practices after adjusting for other variables.

Older women were more likely to practice exclusive breastfeeding compared to younger ( $<20$ years) mothers. This result was consistent with studies in other settings which showed that, younger mothers are at an increased risk of early cessation of exclusive breastfeeding [32-36]. Our findings were also similar to a study conducted in Tanzania where participants who were younger were reported to be less likely to initiate breastfeeding within $1 \mathrm{~h}$ after child delivery [37].

Although maternal level of education and socioeconomic status were found elsewhere to be significantly associated with 24-h recall breastfeeding practices in other studies [38], the current study had not found a statistically significant association between maternal education, socio-economic status and exclusive breastfeeding.

This supported the finding of an earlier study [31] which suggested that educational attainment of mothers was not associated with 6 months exclusive breastfeeding. Nonetheless, the finding of this current study contradicted the results of 6 months exclusive breastfeeding studies in Nigeria [39, 40], Tanzania [37], India [41, 42] and in Ghana [24] which reported that the level of educational attainment of mothers was positively associated with exclusive breastfeeding practice. Perhaps due to the education provided to pregnant women at the well attended antenatal service (87\%) [25], the issue of exclusive breastfeeding has become a universal knowledge hence it is not preserved for only educated women in the study area. 
The high rate of exclusive breastfeeding among the study participants could also be attributed to education from Reproductive and Child Health $(\mathrm{RCH})$ Centers of the Ghana Health Service in the study area where pregnant women receive antenatal care services with education on breastfeeding practices as shown in another study [31].

The findings showed that, mothers who were selfemployed artisans were more likely to practice exclusive breastfeeding. This finding was in line with earlier studies that found self-employed mothers to be more likely to practice 6 months exclusive breastfeeding [43]. This study found that mothers whose households were headed by males were more likely to practice exclusive breastfeeding but this relationship was not statistically significant after adjusting for other explanatory variables. This result was similar to the findings of other studies in Ghana [43] and Malawi [44] where the decision of 6 months and 24 to $26 \mathrm{~h}$ exclusive breastfeeding was influenced by spouses and family members respectively.

Mothers with a family size of four and less were more likely to practice exclusive breastfeeding as compared to those with family size above four.

It was also very intriguing to find that the district of residence was significantly associated with exclusive breastfeeding practice among the study participants. Women from Ningo-Prampram District were 15\% less likely to practice exclusive breastfeeding compared to those from Shai-Osudoku District. This could be ascribed to the introduction of pregnancy schools in health facilities in Shai-Osudoku District where expectant mothers received education, including how to look after themselves and their babies and the importance of exclusive breastfeeding. The effective $\mathrm{RCH}$ in ShaiOsudoku District where pregnant women receive antenatal care services with education on breastfeeding practices could be another contributing factor to the high likelihood of exclusive breastfeeding practice in the ShaiOsudoku District.

\section{Strength and limitations of the study}

Despite the advantage of a large sample and use of population-based data, this study has a number of limitations. First, the outcome was measured based on selfreport; recall bias may have influenced underestimation or overestimation of the association between the outcome of interest and the explanation variables. Social desirability bias could also be a limitation to the study as some women might have withheld what they thought to be negative aspects of their breastfeeding practices which may lead to over estimating the proportion of women who exclusively breastfed for 6 months. The study did not explore other factors such as knowledge, initiation, duration and cultural determinants of exclusive breastfeeding which might have some influence on the outcome of interest. This was primarily due to the limited information in the secondary data used. The study was also limited to only two districts in the Greater Accra Region of Ghana hence, limits the generalizability of the findings.

\section{Conclusions}

The majority of the study participants practiced exclusive breastfeeding. Maternal age, type of occupation, household size and district of residence were strong determinants of exclusive breastfeeding practices.

Maintaining access to information on appropriate breastfeeding practices and promotion of exclusive breastfeeding especially among young mothers in the study area is highly recommended. To further understand other factors influencing the practice of exclusive breastfeeding and to design a suitable evidence-based intervention targeting young mothers, we recommend further qualitative study in this area.

\section{Abbreviations \\ ANC: Antenatal Care; Cl: Confidence Interval; DHDSS: Dodowa Health and Demographic Surveillance System; DHRC: Dodowa Health Research Centre; GDHS: Ghana Demographic Health Survey; JHS: Junior High School; OR: Odd Ratio; PCA: Principal Component Analysis; RCH: Reproductive and Child Health; WHO: World Health Organization}

\section{Acknowledgments}

We sincerely thank the study participants, and staff of the DHDSS for their continuous support to the HDSS. Special appreciate to Prof. Margaret Gyapong who worked tirelessly to establish the Dodowa Health and Demographic Surveillance System.

\section{Authors' contributions}

AKM conceptualized, designed, conducted data extraction and the statistical analysis for the study. He also led the drafting of the paper. AA and DEA contributed to the initial design of the study, literature review and drafting of the paper. JW and MG refined the study design and critically reviewed the paper. All authors read and approved the manuscript.

\section{Funding}

The study has no source of funding.

\section{Availability of data and materials}

All relevant data supporting the conclusions of this article are included within the article. Any additional information is available from the corresponding author on reasonable request.

\section{Ethics approval and consent to participate}

At the beginning of each data collection round, Dodowa Health Research Centre sought verbal consent from household heads and all individual participants as shown in earlier studies [26, 27].

The Ethical Committee of Ghana Health Service and the Institutional Review Board of Dodowa Health Research Centre approved the operations, data collection procedure and quality assurance of the DHDSS [26, 27]. The management of Dodowa Health Research Centre sanctioned the use of data for this study on a condition that the participants' identity remains anonymous.

\section{Consent for publication}

Not applicable.

Competing interests

The authors declare that they have no competing interests. 


\section{Author details}

${ }^{1}$ Dodowa Health Research Centre, Dodowa, Ghana. ${ }^{2}$ Division of Epidemiology and Biostatistics, School of Public Health, University of the Witwatersrand, Johannesburg, Parktown, South Africa. ${ }^{3}$ University of Health and Allied Sciences, Ho, Volta Region, Ghana. ${ }^{4}$ Ghana Health Service, Accra, Ghana.

Received: 29 April 2019 Accepted: 4 February 2020

Published online: 07 February 2020

\section{References}

1. Rollins NC, Bhandari N, Hajeebhoy N, Horton S, Lutter CK, Martines JC, et al. Why invest, and what it will take to improve breastfeeding practices? Lancet. 2016;387(10017):491-504.

2. Victora CG, Bahl R, Barros AJD, França GVA, Horton S, Krasevec J. Breastfeeding in the 21st century: epidemiology, mechanisms, and lifelong effect. Lancet. 2016:387(10017):475-90.

3. Sullivan AO, Farver M, Smilowitz JT. The influence of early infant-feeding pratices on the intestinal microbiome and body composition in infants. Nutr Metab Insights. 2015;8(1):87.

4. UNICEF, WHO. Indicators for assessing infant and young child feeding practices. In: Part 1 Definitions. Geneva: World Health Organization; 2008.

5. Arts M, Mehra V, Taylor G, Krasevec J, Hayashi C, Bégin F, et al. Breastfeeding a Mother's gift, for every child. New York: UNICEF; 2018

6. Chowdhury R, Sinha B, Sankar MJ, Taneja S, Bhandari N, Rollins N, et al. Breastfeeding and maternal health outcomes: a systematic review and meta-analysis. Acta Paediatr. 2015;104(467):96-113.

7. Jones G, Steketee RW, Black RE, Bhutta ZA, Morris SS. How many child deaths can we prevent this year? Lancet. 2003;362(9377):65-71.

8. Black RE, Alderman H, Bhutta ZA, Gillespie S, Haddad L, Horton S, et al. Maternal and child nutrition: building momentum for impact. Lancet. 2013; 382:372-5

9. Black RE, Victora CG, Walker SP, Bhutta ZA, Christian P, de Onis M, et al. Maternal and child undernutrition and overweight in low-income and middle-income countries. Lancet. 2013;382(9890):427-51.

10. Black RE, Allen LH, Bhutta ZA, Caulfield LE, de Onis M, Ezzati M, et al. Maternal and child undernutrition: global and regional exposures and health consequences. Lancet. 2008;371(9608):243-60.

11. Agunbiade OM, Ogunleye OV. Constraints to exclusive breastfeeding practice among breastfeeding mothers in Southwest Nigeria: implications for scaling up. Int Breastfeed J. 2012;7:5.

12. Schmied V, Barclay L. Connection and pleasure, disruption and distress: Women's experience of breastfeeding. J Hum Lact. 1999;15(4):325-34.

13. Gartner LM, Morton J, Lawrence RA, Naylor AJ, O'Hare D, Schanler RJ, et al. American Academy of Pediatrics section on breastfeeding: breastfeeding and the use of human milk. Pediatrics. 2005;115:496-506.

14. Ogunlesi TA. Maternal socio-demographic factors influencing the initiation and exclusivity of breastfeeding in a Nigerian semi-urban setting. Matern Child Health J. 2010;14(3):459-65.

15. Otoo GE, Lartey AA, Pérez-Escamilla R. Perceived incentives and barriers to exclusive breastfeeding among Periurban Ghanaian women. J Hum Lact. 2009:25(1):34-41.

16. Horta B, Victora C, World Health Organization. Short-term Effects of breastfeeding: a systematic review on the benefits of breastfeeding on diarrhoea and pneumonia mortality. In: World Health Organization. Geneva: World Health Organization; 2013. p. 1-54.

17. Lamberti LM, Zakarija-Grkovi I, Walker CLF, Theodoratou E, Nair H, Campbell $\mathrm{H}$, et al. Breastfeeding for reducing the risk of pneumonia morbidity and mortality in children under two: a systematic literature review and metaanalysis. BMC Public Health. 2013;13:S18.

18. Hanieh S, Ha T, Simpson JA, Thuy TT, Khuong NC, Thoang DD, et al. Exclusive breast feeding in early infancy reduces the risk of inpatient admission for diarrhea and suspected pneumonia in rural Vietnam: a prospective cohort study. BMC Public Health. 2015;15:1166.

19. Nkemjika SO, Demissie K. Breast feeding initiation time and its impact on diarrheal disease and pneumonia in West Africa. J Public Health Epidemiol. 2015;7:352-9.

20. Lamberti LM, Walker CLF, Noiman A, Victora C, Black RE. Breastfeeding and the risk for diarrhea morbidity and mortality. BMC Public Health. 2011;11:S15.

21. Mgongo M, Hussein TH, Stray-Pedersen B, Vangen S, Msuya SE, Wandel M. "We give water or porridge, but we don't really know what the child wants:
" a qualitative study on women's perceptions and practises regarding exclusive breastfeeding in Kilimanjaro region, Tanzania. BMC Pregnancy Childbirth. 2018;18:323.

22. Yalcin SS, Berde AS, Yalcin S. Determinants of exclusive breastfeeding in sub Saharan Africa: a multilevel approach. Paediatr Perinat Epidemiol. 2016;30(5): 439-49.

23. Ghana Statistical Service (GSS), Ghana Health Service (GHS), ICF: Ghana Maternal Health Survey 2017:Key Findings. In.: ICF, Rockville, Maryland, USA: GSS, GHS, and ICF; 2018.

24. Ghana Statistical Service. Ghana Multiple Indicator Cluster Survey with an enhanced Malaria Module and Biomarker 2011. In. Accra: Ghana Statistical Service; 2012

25. Ghana Statistical Service (GSS), Ghana Health Service (GHS), ICF International. Ghana Demographic and Health Survey 2014. Rockville: GSS, GHS, ICF International; 2015.

26. Manyeh AK, Amu A, Akpakli AE, Williams J, Gyapong M. Socioeconomic and demographic factors associated with caesarean section delivery in southern Ghana: evidence from INDEPTH network member site. BMC Pregnancy Childbirth. 2018:18:404

27. Manyeh AK, Kukula V, Odonkor G, Ekey RA, Adjei A, Narh-Bana S, et al. Socioeconomic and demographic determinants of birth weight in southern rural Ghana: evidence from Dodowa health and demographic surveillance system. BMC Pregnancy Childbirth. 2016;16:160.

28. Awini E, Sarpong D, Adjei A, Manyeh AK, Amu A, Akweongo P, et al. Estimating cause of adult (15+years) death using InterVA-4 in a rural district of southern Ghana. Glob Health Action. 2014;7(1):25543.

29. Gyapong M, Sarpong D, Awini E, Manyeh KA, Tei D, Odonkor G, et al. Health and demographic surveillance system profile: the Dodowa HDSS. Int J Epidemiol. 2013;42:1686-96.

30. Begin F, Arts M, White J, Clark D, Sint TT, Taqi I, et al. From the first hour of life - making the case for improved infant and young child feeding everywhere. New York: UNICEF; 2016.

31. Boakye-Yiadom A, Yidana A, Sam NB, Kolog B, Abotsi A. Factors associated with exclusive breastfeeding practices among women in the west Mamprusi District in northern Ghana: a cross-sectional study. Public Health Research. 2016:6(3):91-8.

32. Avery M, Duckett L, Dodgson J, Savik K, Henly SJ. Factors associated with very early weaning among primiparas intending to breastfeed. Matern Child Health J. 1998;2:167-79.

33. Hauck YL, Fenwick J, Dhaliwal SS, Butt J. A Western Australian survey of breastfeeding initiation, prevalence and early cessation patterns. Matern Child Health J. 2011:15:260-8.

34. Liu P, Qiao L, Xu F, Zhang M, Wang Y, Binns CW. Factors associated with breastfeeding duration. J Hum Lact. 2013;29:253-9.

35. Kaneko A, Kaneita Y, Yokoyama E, Miyake T, Harano S, Suzuki K, et al. Factors associated with exclusive breast-feeding in Japan: for activities to support child-rearing with breast-feeding. J Epidemiol. 2006;16:57-63.

36. Ludvigsson JF, Ludvigsson J. Socio-economic determinants, maternal smoking and coffee consumption, and exclusive breastfeeding in 10205 children. Acta Paediatr. 2005;94:1310-9.

37. Victor R, Baines SK, Agho KE. Determinants of breastfeeding indicators among children less than 24 months of age in Tanzania: a secondary analysis of the 2010 Tanzania Demographic and Health Survey. BMJ Open. 2013;3:e001529

38. Aidam BA, Pérez-Escamilla R, Lartey A, Aidam J. Factors associated with exclusive breastfeeding in Accra, Ghana. Eur J Clin Nutr. 2005;59:789-96.

39. Ogbonna C, Okolo AA, Ezeogu A. Factors influencing exclusive breastfeeding in Jos, plateau state, Nigeria. West Africa J Med. 2000;19:107-10.

40. Aghaji MN. Exclusive breastfeeding practice and associated factors in Enugu Nigeria. West Afr J Med. 2002;21:66-9.

41. Patel A, Badhoniya N, Khadse S, Senarath U, Agho KE, Dibley MJ. Infant and young child feeding indicators and determinants of poor feeding practices in India: secondary data analysis of National Family Health Survey 2005-06. Food Nutr Bull. 2010:31:314-33.

42. Chudasama RK, Patel PC, Kavishwar AB. Determinants of exclusive breastfeeding in South Gujarat region of India. J Clin Med Res. 2009;1 (2): 102-8.

43. Mensah KA, Acheampong E, Anokye FO, Okyere P, Appiah-Brempong E, Adjei RO. Factors influencing the practice of exclusive breastfeeding among nursing mothers in a peri-urban district of Ghana. BMC Res Notes. 2017:10: 466. 
44. Kent CJ, Mitoulas RL, Cregan DM, Ramsay TD, Doherty AD, Hartmann EP. Volume and frequency of breastfeedings and fat content of breast milk throughout the day. Pediatrics. 2006;117(3):e387-95.

\section{Publisher's Note}

Springer Nature remains neutral with regard to jurisdictional claims in published maps and institutional affiliations.

Ready to submit your research? Choose BMC and benefit from:

- fast, convenient online submission

- thorough peer review by experienced researchers in your field

- rapid publication on acceptance

- support for research data, including large and complex data types

- gold Open Access which fosters wider collaboration and increased citations

- maximum visibility for your research: over $100 \mathrm{M}$ website views per year

At BMC, research is always in progress. 